
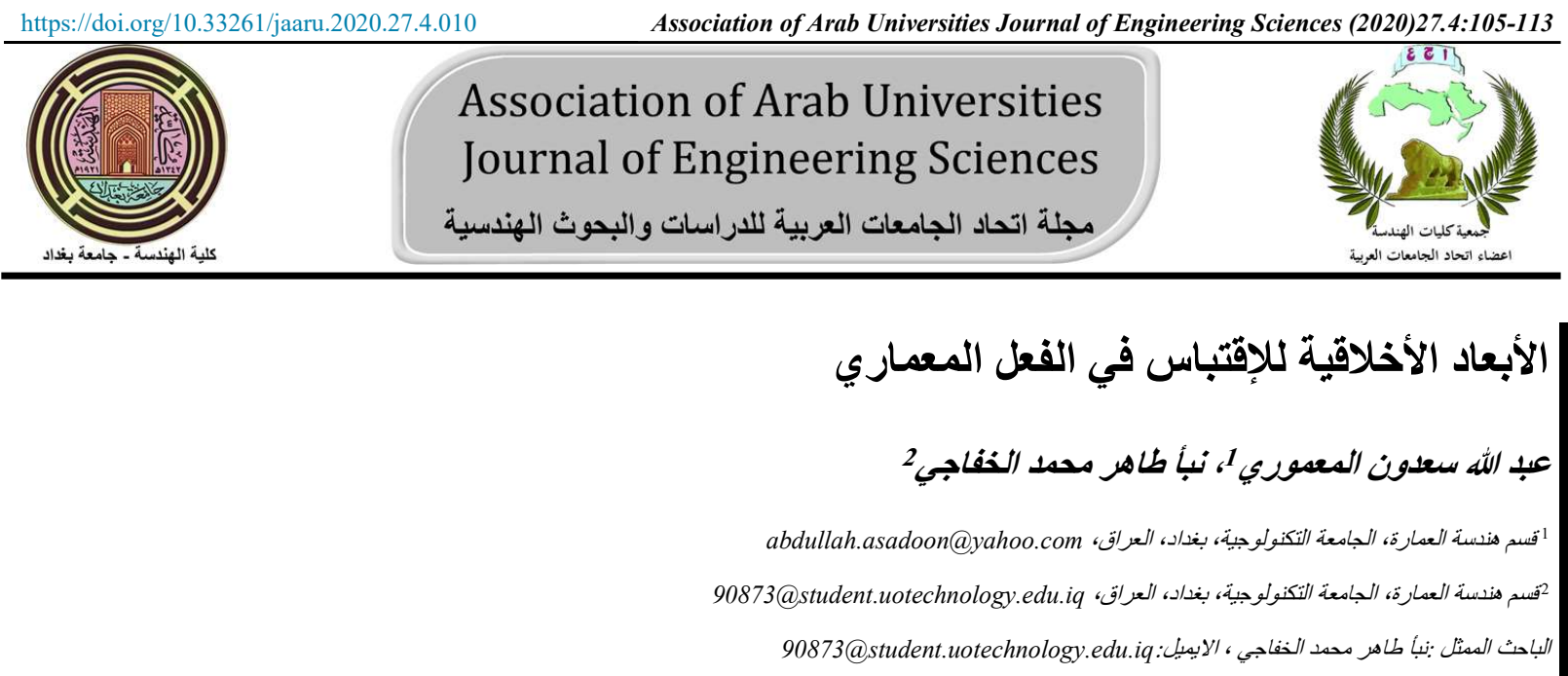

نشر في :31 كانون الاول 2020

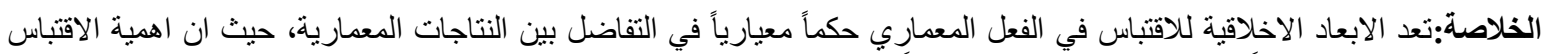

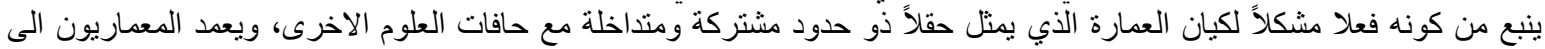

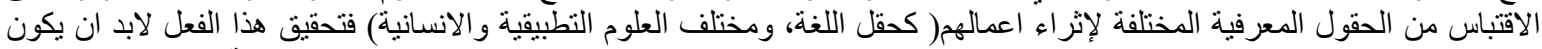

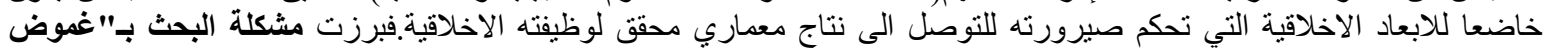

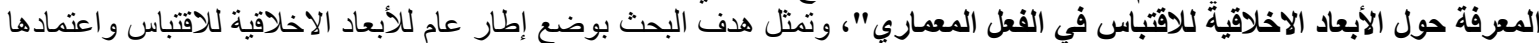

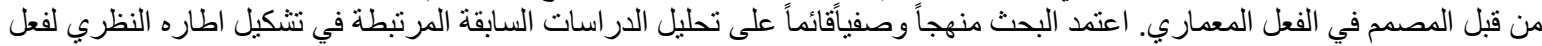

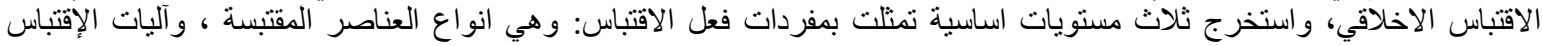

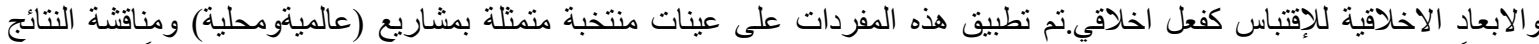

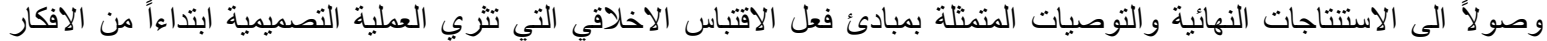
وصو لا الى النتائج النهائية.

الكلمات المفتاحية:الاقتباس ، الابعاد الاخلاقية ، الفعل المعماري

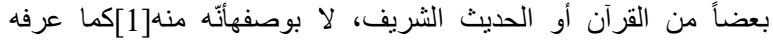

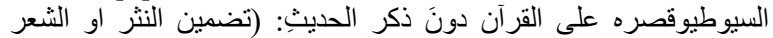

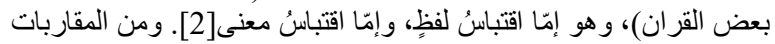

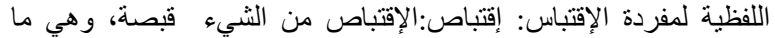

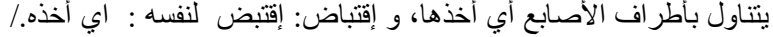
و إقتبال: إقتبل الكلام، اي ارتجله.

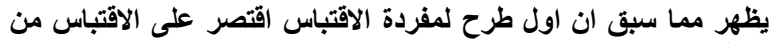

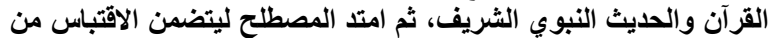

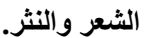

Quotation:a phrase or short piece of writing taken from a longer work of literature, poetry, etc. [3]. Ex:ensure you receive a written quotation covering all aspects of the topic.

$$
\text { مقاريات المغنى لدفردة الإقتباس: }
$$

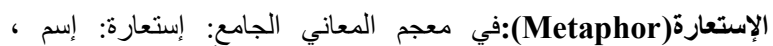

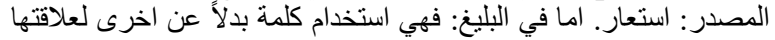

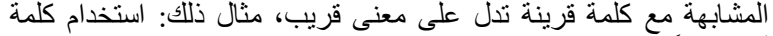

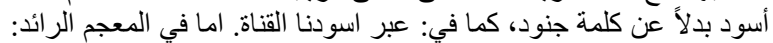

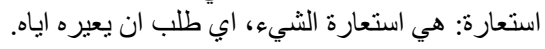

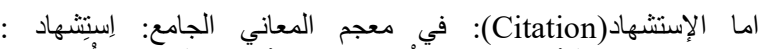

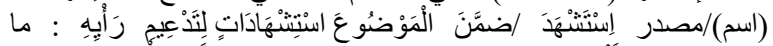

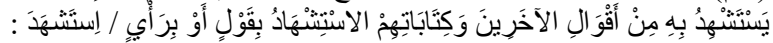

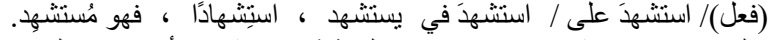
والفرق بين الاستشهاد و الاقتباس في الخطبة:فالاستشهاد يأتي عقب الفكرة

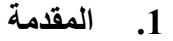

يعد حقل اللغة من ابرز الحقول المعرفية التي تنهل منها العمارة لامكانية

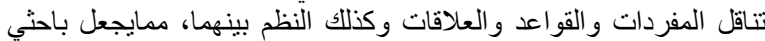

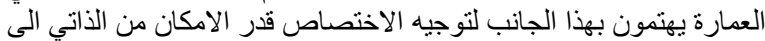

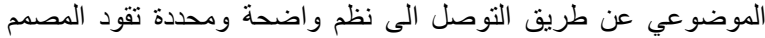

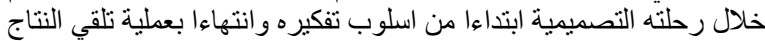

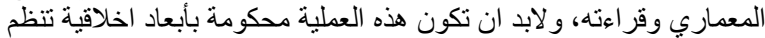

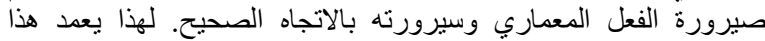

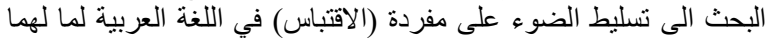

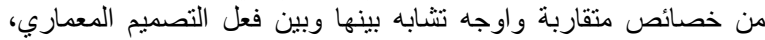

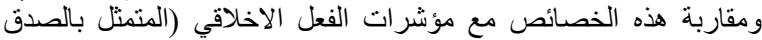

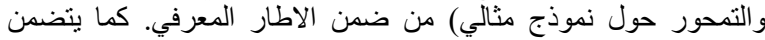

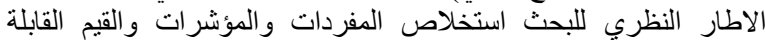

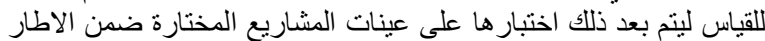

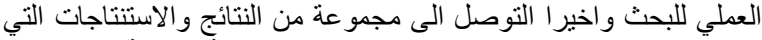

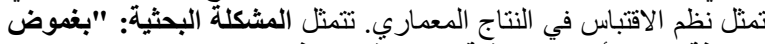

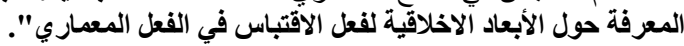

بهذا سبكون هدف البحث متمثل بوضع إطار عام للأبعاد الاخلاقية للاقتباس واعتمادها من قبل المصمم في الفعل المعماري.

$$
\text { 2. }
$$

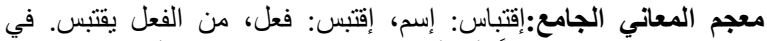

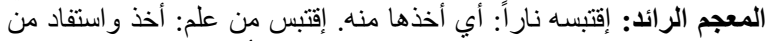

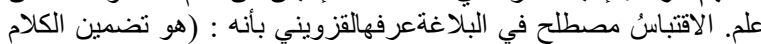




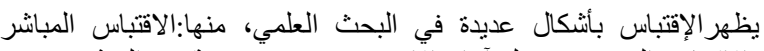

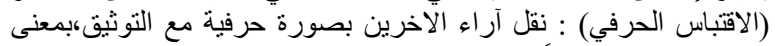

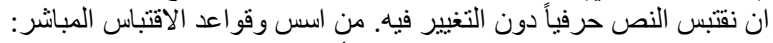

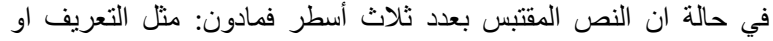

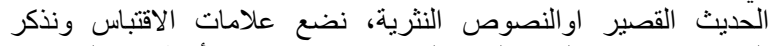

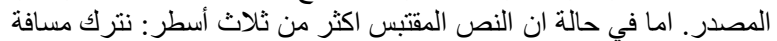

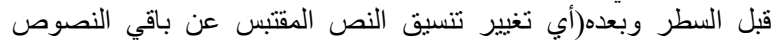

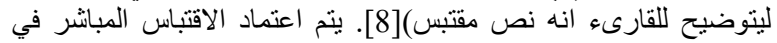

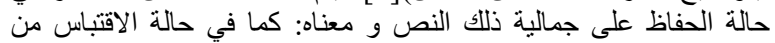

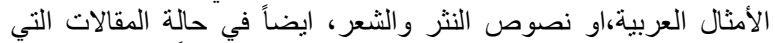

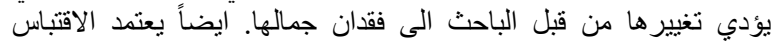

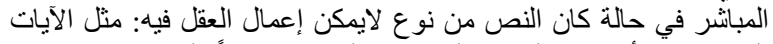

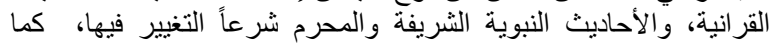
يفضل فيالايات القرانية أن يتم تثبيتهابالخط العثماني من الكمبيوتر لتجنب

الخطأ فيه [9] فيالات

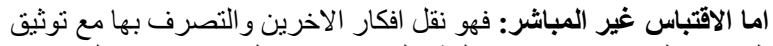

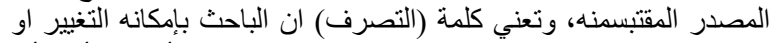

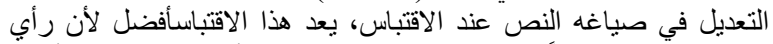

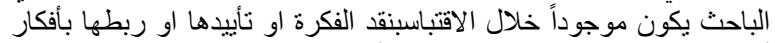

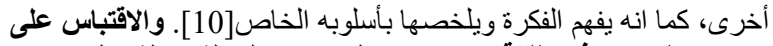

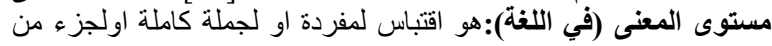

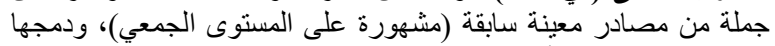

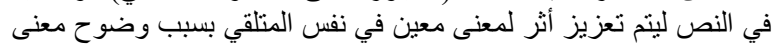

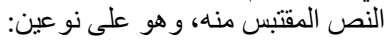

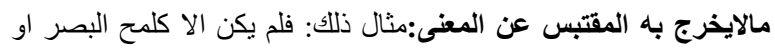

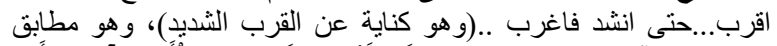

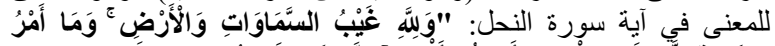

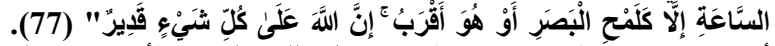

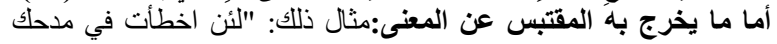

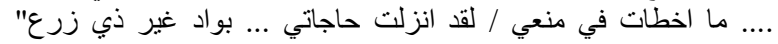

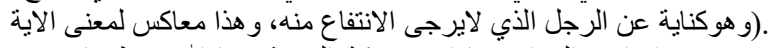

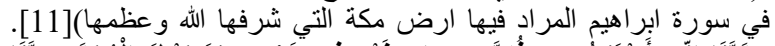

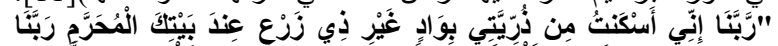

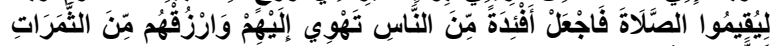

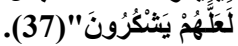

\section{تتمثل شروط الاقتباس في البحث العلمي[12] :}

الإشارة الصريحة الى المرجع المقتبس منه، و ذكر المعنى الاصلي المكي

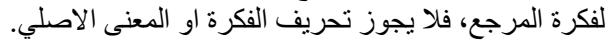

ضرورة ان يشتمل الاقتباس على الشواهد المؤيدة لرأي الباحث، و ايضاً الشو اهد التي تمثل وجهات نظر مختلفة.

لابد ان يظهر في البحث إسهامات للباحث، فلا يجوز ان يكون البحث

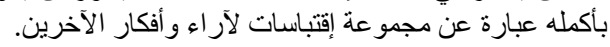

تنسيق الاقتباس بحيث يذكر بشيء من التقديم والتعليق من قبل الباحث.

ضرورة الانسجام بينذ ماتم اقتباسه وماقبله وبعده فلا يكون هناك تنافر

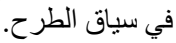

تجنب السرقات العلمية او الادبية وبما بسيئ لسمعة الباحث

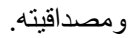

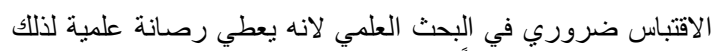

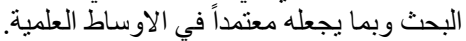

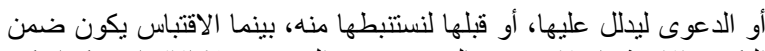

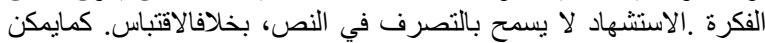

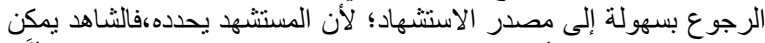

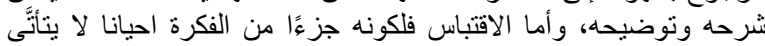

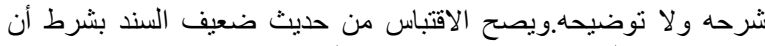

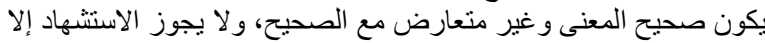

بالصحيح [4].

والتضمين(inclusion):في معجم المعاني الجامع: التضمين: اسم وجمعيه

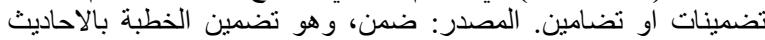

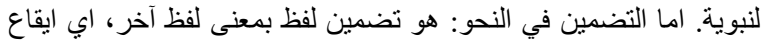

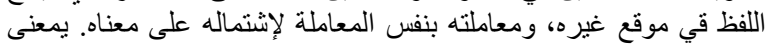

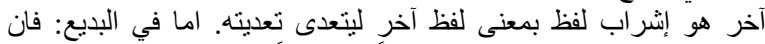

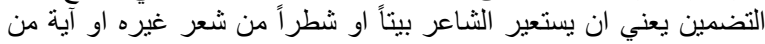

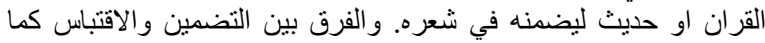

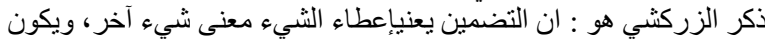

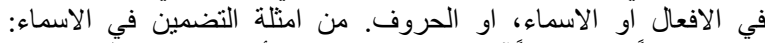

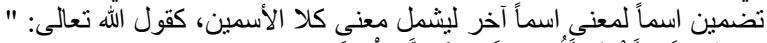

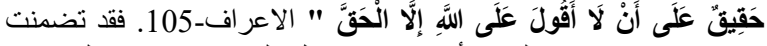

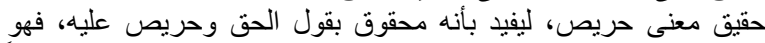

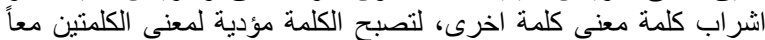

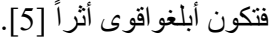

التناص(Intertextuality):معجم المعاني الجامع: تَنَاصّ: إسم. تناص

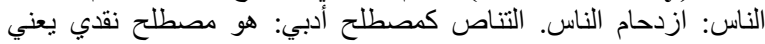

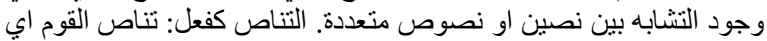

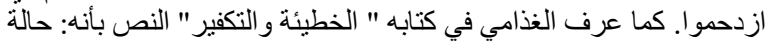

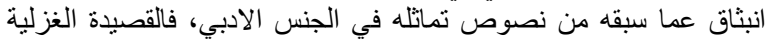

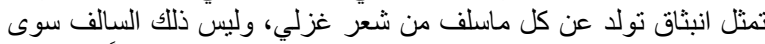

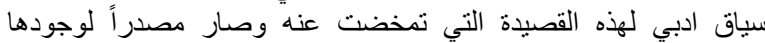

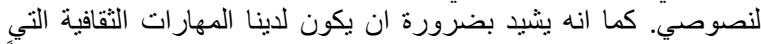

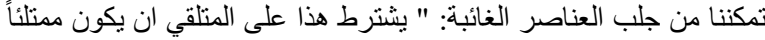

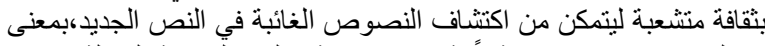

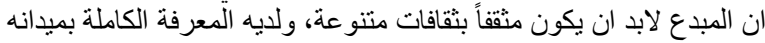

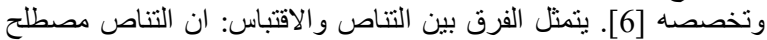

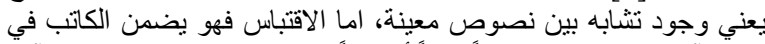

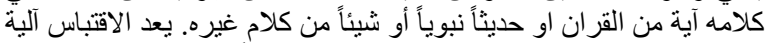

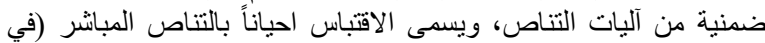

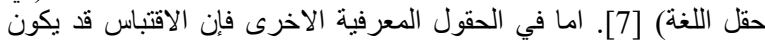
غير مباشر يمتد الى ماور اء الثكل نحو الافكار و المضامين.

مما سبق نستخلص ان لمفهوم الاقتباس مقاربات على مستوى المعنى

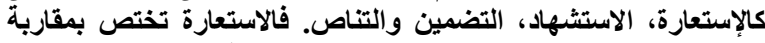

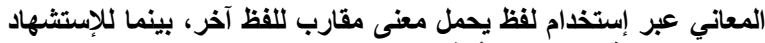

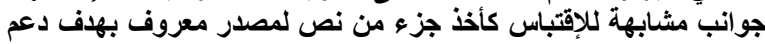

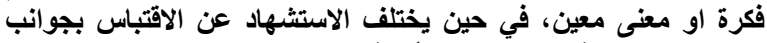

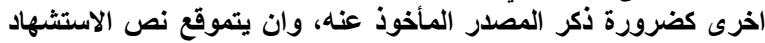

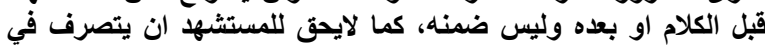

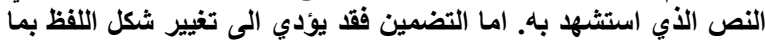

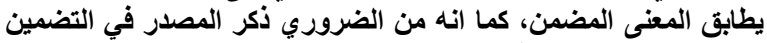

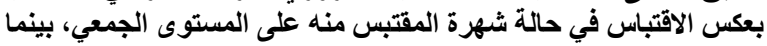

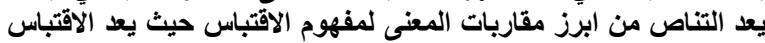

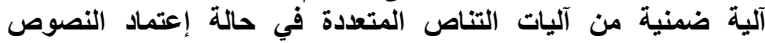
المقتبسة بصورة مباشرة.

الاقتباس إصطلاحاً: - إن

2.3

1.3.2 الاقتباس في البحوث العلمية، والاعمال الادبية.يعد فعل

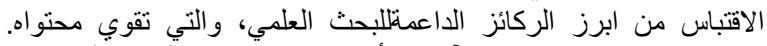

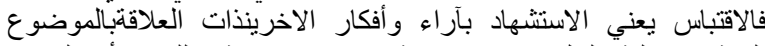
البحثي،و عملية النقل قد تكونحرفية او غير حرفية للنص أو الفكرة، 


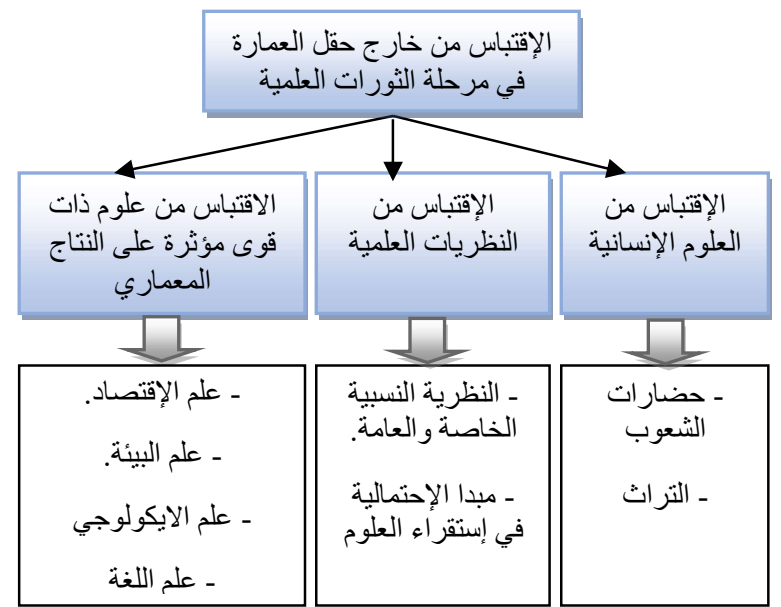

مخطط 2: يوضح مصادر الاقتباس من خارج حقل العمارة في مرحلة البانة الثور ات العلمية. المصدر: الباحثنان.

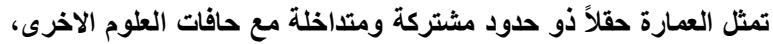

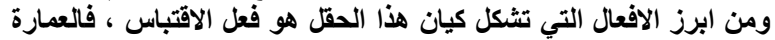

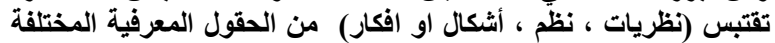

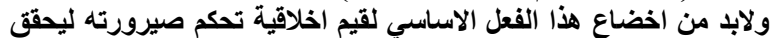
وظيفته الاخلاقية في العمارة.

2.2.3.2 الاقتباس من د/خل حقل العمارة:يظهر فعل الإقتباس في النتاجات

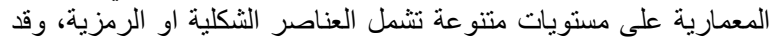
يكون الاقتباس على مستوى عنصر و واحد او أكثر، وسيتم في هذه الفئن الفقرة

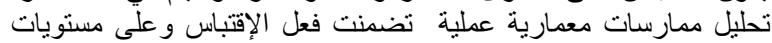

مختلفة.

ـ قصر عشة في اليمن 1930:يقع القصر في مدينة تريم اليمينةوتم تتفيذه

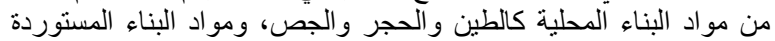

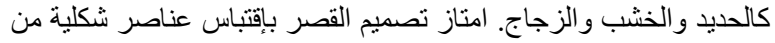

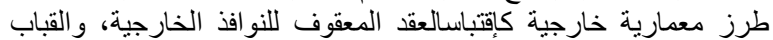

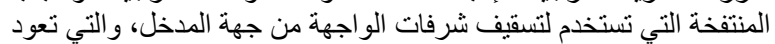

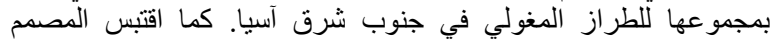

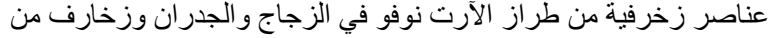

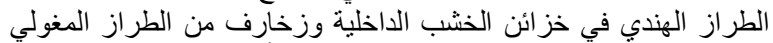

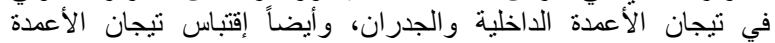

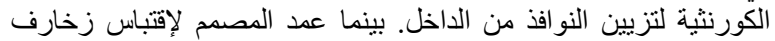

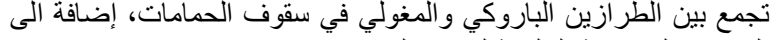

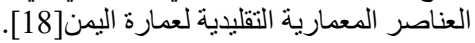
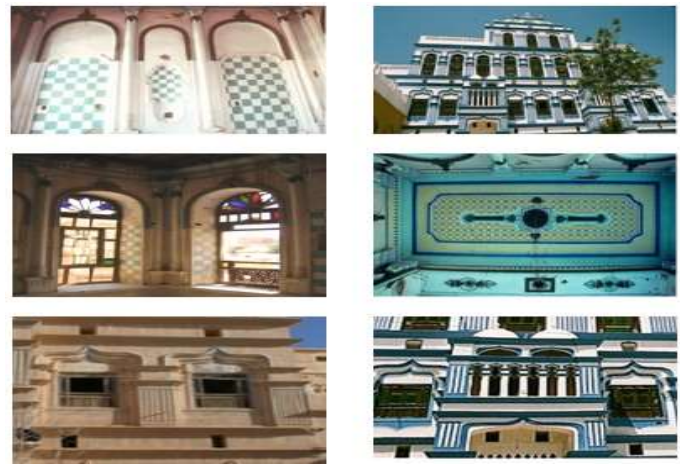

الثكل 1: إقتباس عناصر معمارية شكلية من مصادر متنو عة في قصر

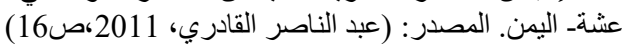

2.3 .2 الاقتباس في العمارة:ييرز الاقتباس كفعلمكل لكيان العمارة

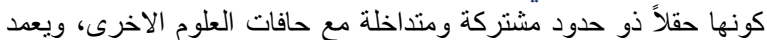

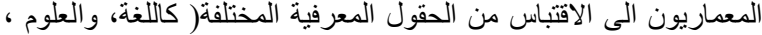

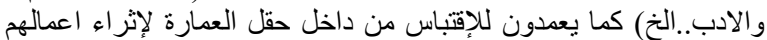
سواء في الجانب النظري او التطبيقيق لإنبان

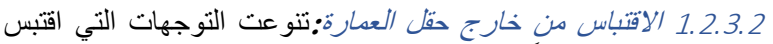

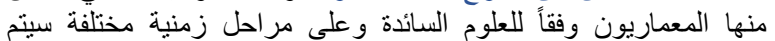

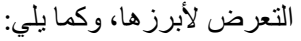

ـ مرحلة الثورة الصناعية: بدأت العمارة بالإنفتاح على الحقول المعرفية

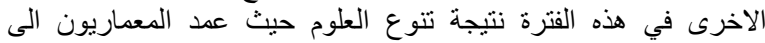

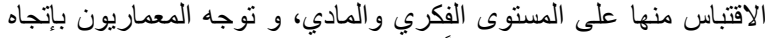

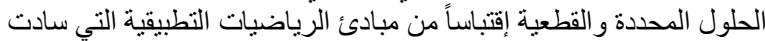

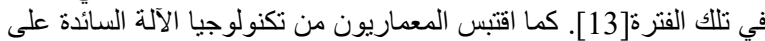

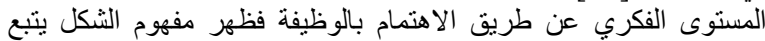

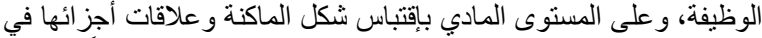

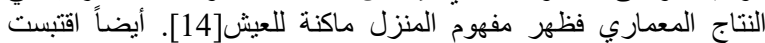

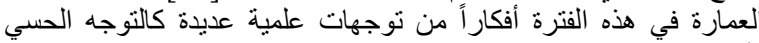

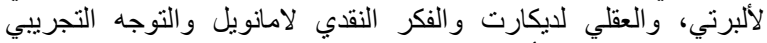

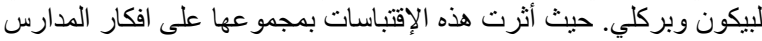

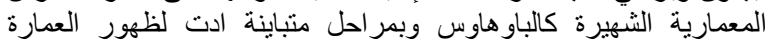

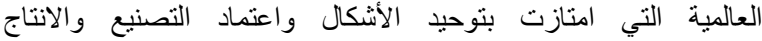
المقيس[15]. كما في المخطط التالى:

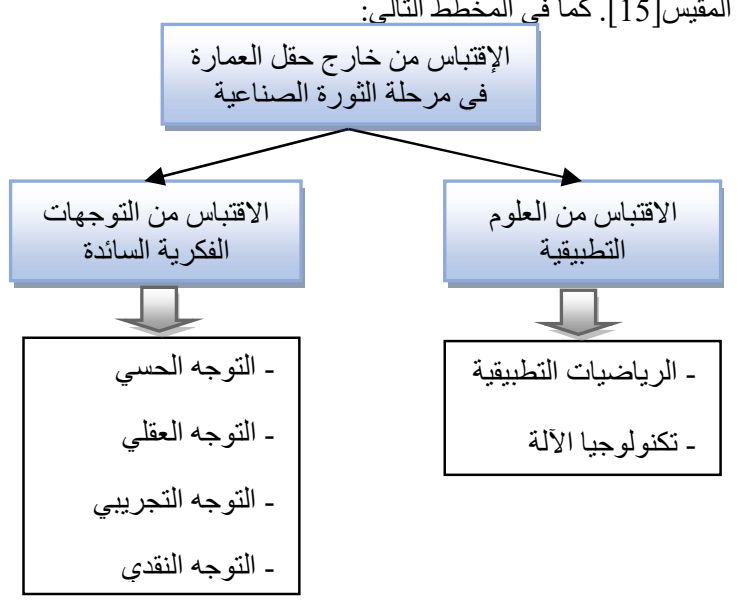

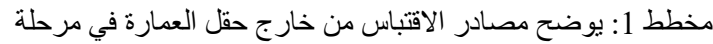
الثورة الصناعية. المصدر : الباحثنان.

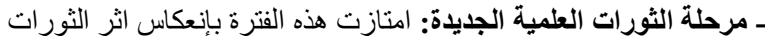

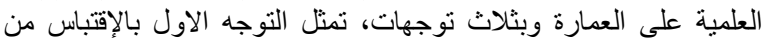

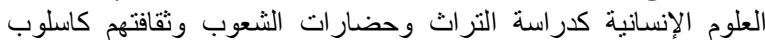

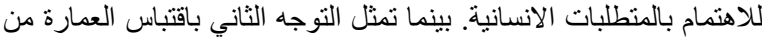

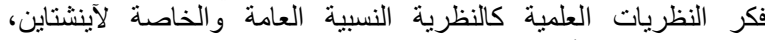

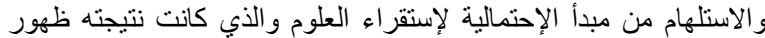

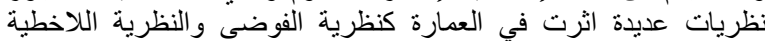

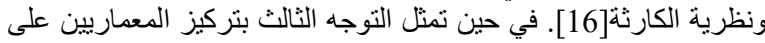

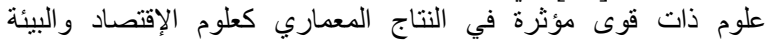

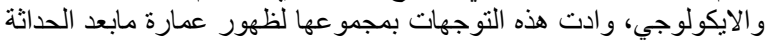

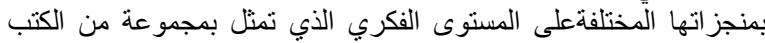

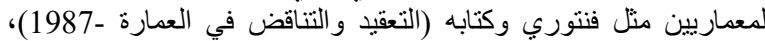

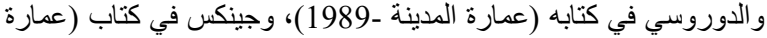

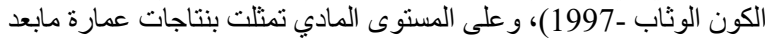

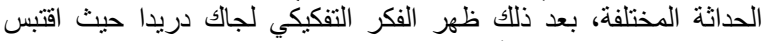

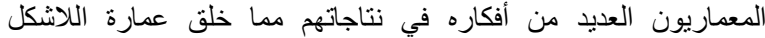
و اللاوظيفة واللامعنى [17]. وكما في المخطط في التالي: 


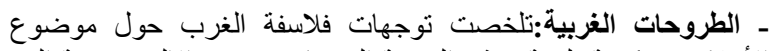

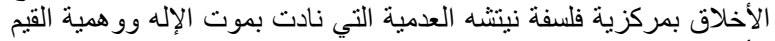

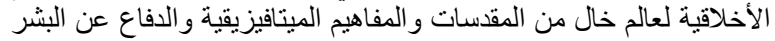

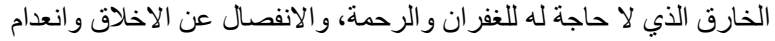

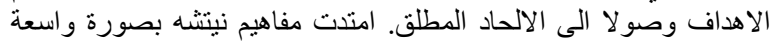

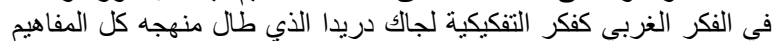

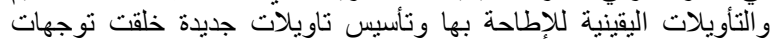

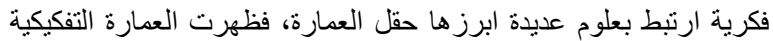

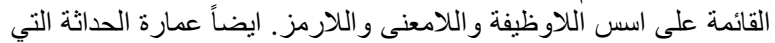

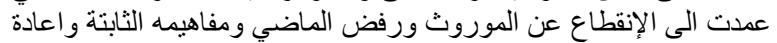

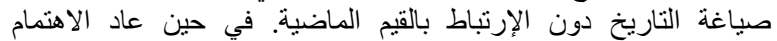

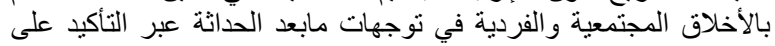

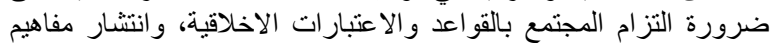

التكافل وحسن النية وتغليب الموضورية على الفردية [22].

ـ الطروحات الإسلامية:فسرت الطروحات الاسلامية موضوع الاخلاق

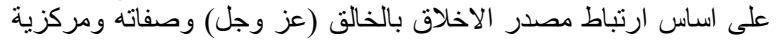

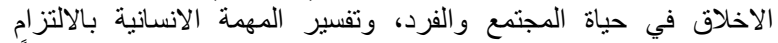

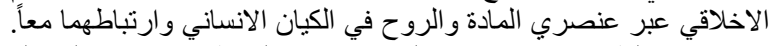

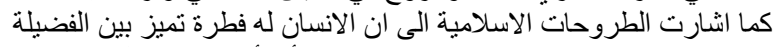

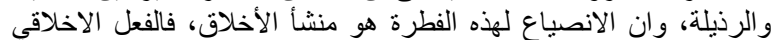

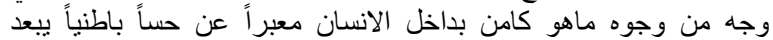

الانسان عن الرذائل ليستكمل سعادنه [23].

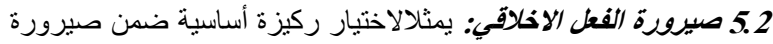

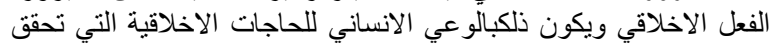

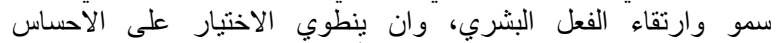

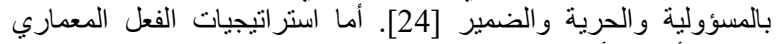

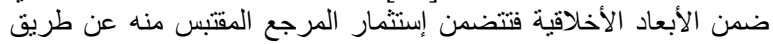

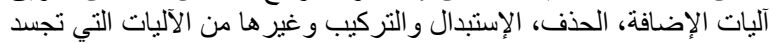

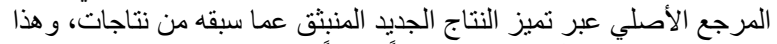

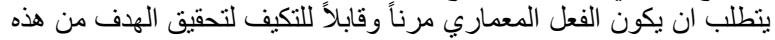

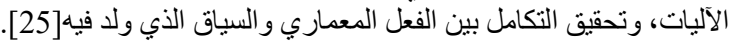

ـ خلاصة المحور الأول (الاطار المعرفي): مما سبق نتوصل الى التعريف الإجر ائي لفعل الاقتباس في العمارة:

"هو الفعل الناشئ من نقل الاشكال والافكار من داخل وخارج حقل العمارة

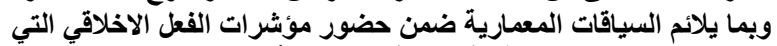

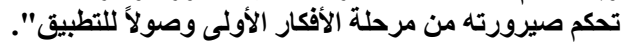

$$
\text { نقد الاراسات السابقة: }
$$

بمجمل الطرح السابق يتبين مركزية فعل الاقتباس في تشكيل كيان العمارة

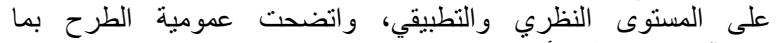

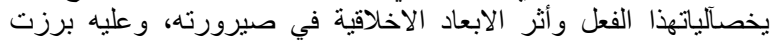

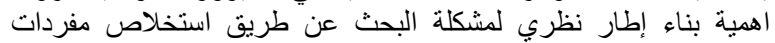
ومؤشر اتمن الدراسات السابقة المرتبطة بالاقتباس والفي طن الفعل الاخلافي.

1.3 الدراسات السابقة المرتبطة بالإقتباس:بمجمل ماطرح في الدراسات

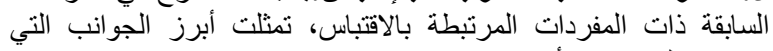

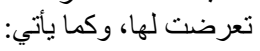

1972 Candelsonas\& Morton)

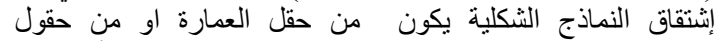

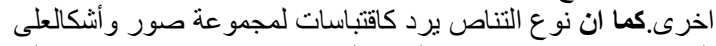

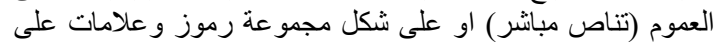
وجه الخصوص (تناص غير )ول مباشر).ويرد التناص كعملية اختيار

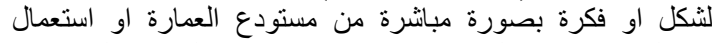

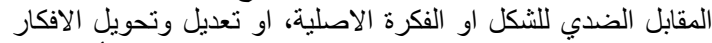
والاشكال القديمة لتوليد اخرى جديدة، وعليه فالتناص بأنيل لبنيل البناء
- متحف الاطفال في هيوستن - روبرت فنتوري 1992:اقتبس المعماري

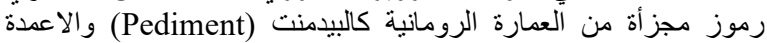
الدورية (Doric) و أخضعها لمعالجات على مستوى اللورن اللون و الحجم بطريقة

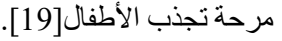
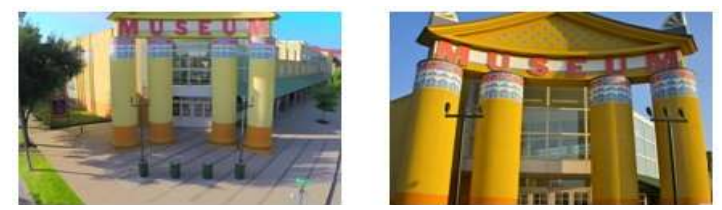

الثكل 2: إقتباس عناصر شكلية من العمارة الرومانية في متحف هيوسنن للاطفال. المصدر: (http:/www.cmhouston.org

- جامع الكبيسي في بغداد 1985م: اقتبس المصمم عناصر معمارية تمثلت

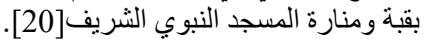
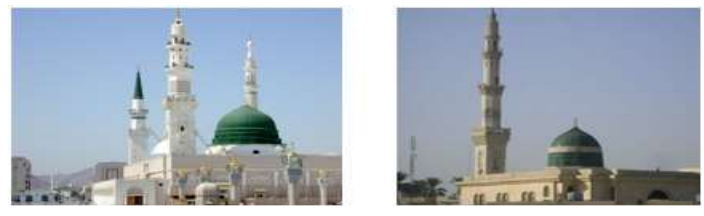

الثكل 3: اقتباس قبة ومنارة المسجد النبوي الثريف في تصميم جامع

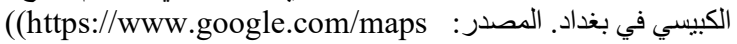

ـ تصميم مبنى الامانة العامة لمجلس الوزراء في بغداد:فاز التصميم

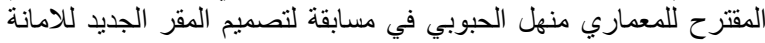

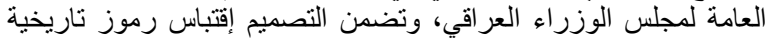

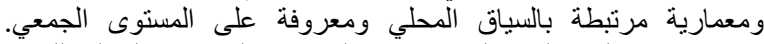

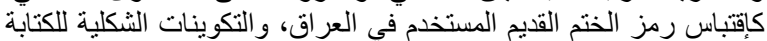

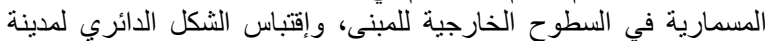

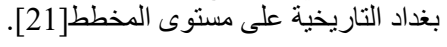
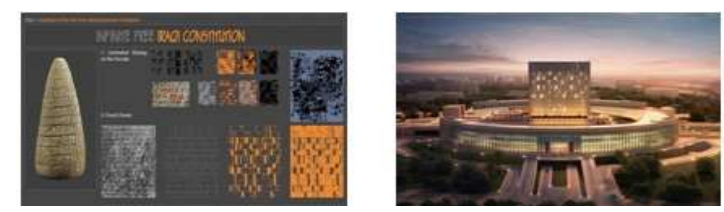

الثكل 4: إقتباس رموز من التاريخ المحلي في تصميم مبنى الامانة العامة

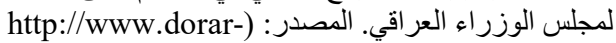
(aliraq.net/threads/52469

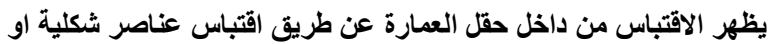

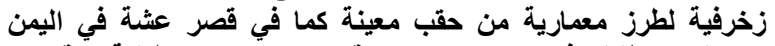

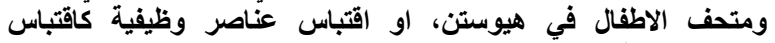

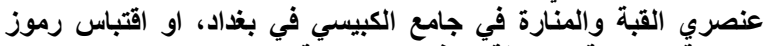

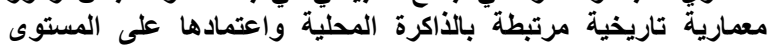

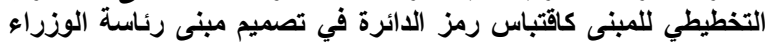

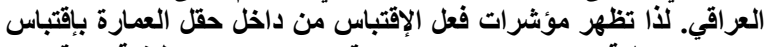

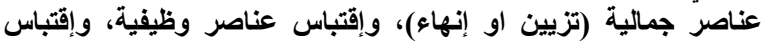
عناصر شكلية.

4.2 الإطار المعرفي للفعل الاخلاقي: حظيت المفاهيم الاخلاقية بإهتمام كبير

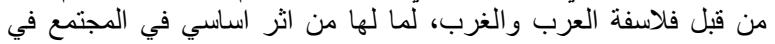

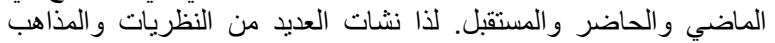

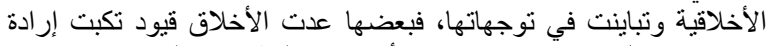

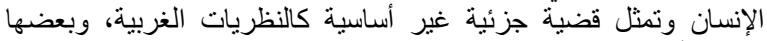

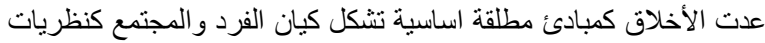

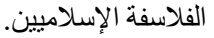


بالمصمم وتوجهاته الفكرية وكيفية تعامله مع القيم الاخلاقية وفقاً

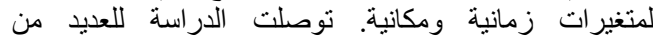

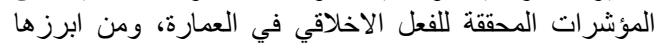

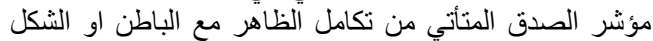

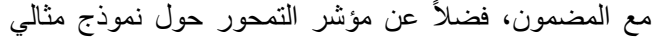
(مطلق) كمرجع ثابت يقتبس منه المصدم على على المستوى المادي

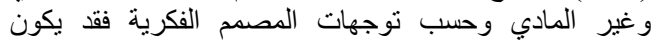

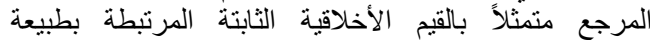

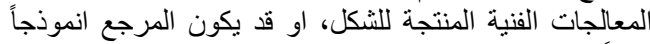

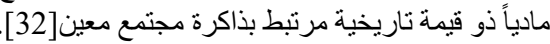

(عماد لافي، 2009):الفعل المعماري الذي يمارسه المصمم في دئ دئي

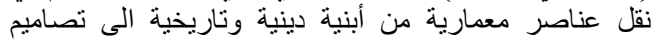

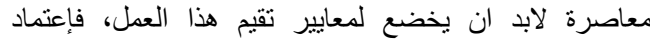

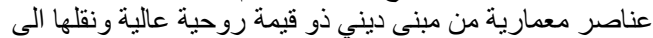

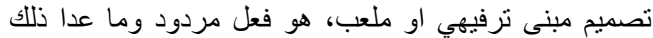

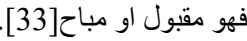

William M. Taylor and Michael P. Levine, )

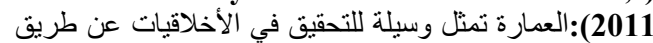

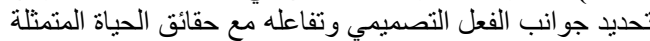

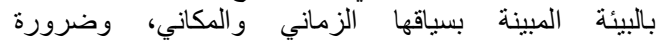

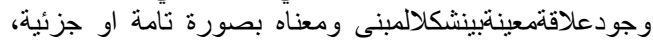

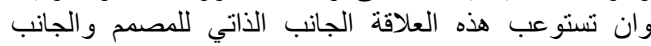
الموضوعي الذي يمثل نتيجة لتفاعل نطاقات متعددةاجتماعية

ونفسية و اقتصادية] [34].

تبرز مماسبق جوانب عديدة للفعل الأخلاقي في العمارة تتمثل بمؤشرات

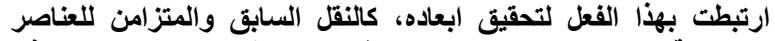

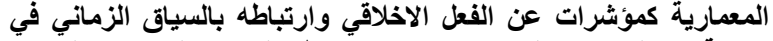

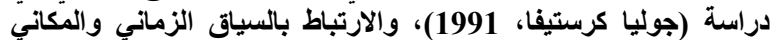

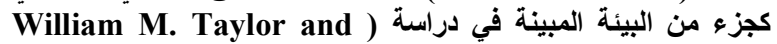

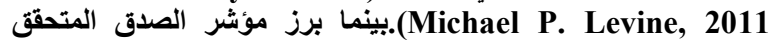
بتطابق الثكل مع المضمون وعلى ثُلاث انواع المقبول والمباح المباح والمردود

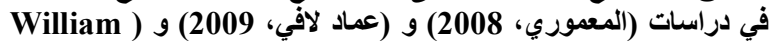

.M. Taylor and Michael P. Levine, 2011 جدول 1: مفردات الإطار النظري، المصدر: الباحثان.

\begin{tabular}{|c|c|c|c|c|}
\hline \multicolumn{3}{|c|}{ القيم الممكنة } & المؤشر ات & المفردات \\
\hline 1 & & & وظناصية & العناصر أنواع \\
\hline 2 & & & شناصرة & \\
\hline 3 & \multicolumn{2}{|c|}{ إنهاء } & عناصر & \\
\hline 4 & \multicolumn{2}{|c|}{ تزيين } & & \\
\hline 5 & من داخل حقل & المرجع & الإنتخاب & \\
\hline 6 & من خارج حقل & & & \\
\hline 7 & تاريخية & نوع الحقبة & & الاقتباس \\
\hline 8 & معاصرة & & & \\
\hline 9 & معالم العمارة & المعالم & & \\
\hline
\end{tabular}

الثكل من خلال بناء المعنى بتحديد الاقتباس وعلاقات الارتباط بين

النصوص[26].

1986 Sakamoto)

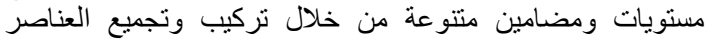
كنص، واستثمار فكرة العمارة كنص في العملية التصميمية باعتبار

الفضاءات كنصوص[27 كنصار فكرة العمارة

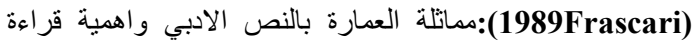

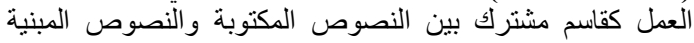

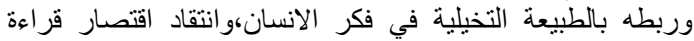

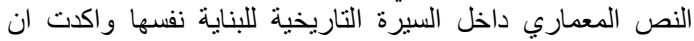

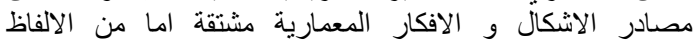
والاساليب المهجورة او من الثورات العلمية[28].

(البستاني 1996): تعريف مفهوم التناص بانه تعالق (دخول في

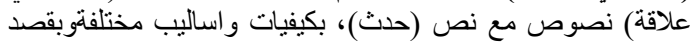

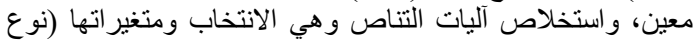

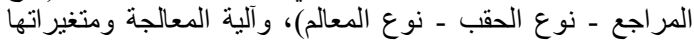

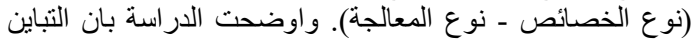

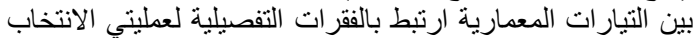

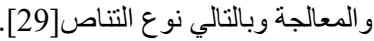

(عماد لافي 2009):تحويل مفردة الاقتباس من اللغة الى العمارة،

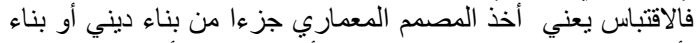

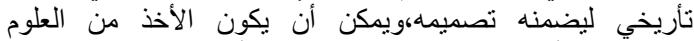

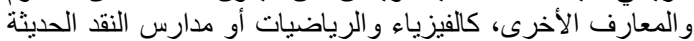

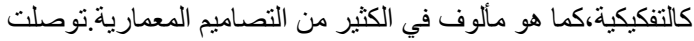

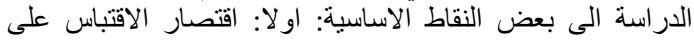

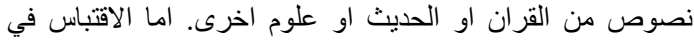

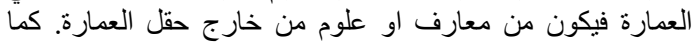

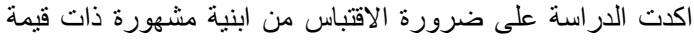

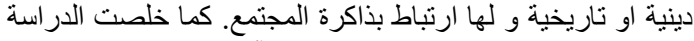

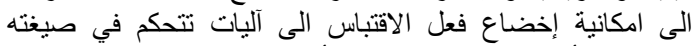

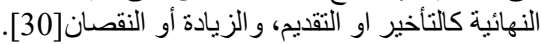

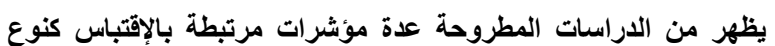

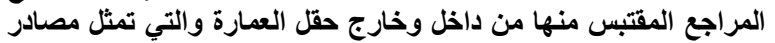

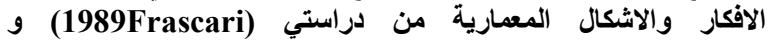
الإع) الإقتباس كآلية الاتتخاب والمعالجة ومتغيراتها من دراستة (البستئاني

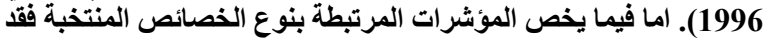

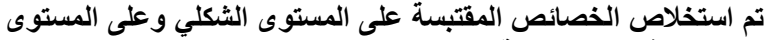

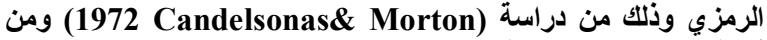

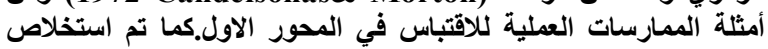

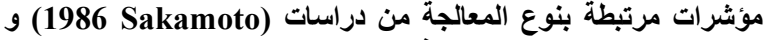

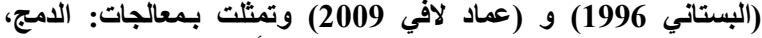
التركيب، التجميع، الزيادة، النقصان، التقديم والتأخير.

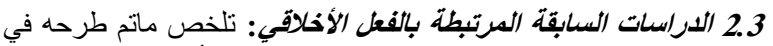
الدراسات السابقة ذات المفردات المرتبطة بالفعل الإلة الأخلافي في العمارة

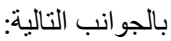

(جوليا كرستيفا، 1991): تعرضت الدر اسة لإعتبار ات مرتبطة

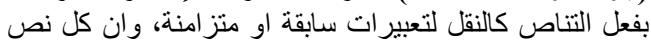

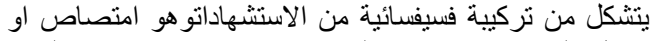

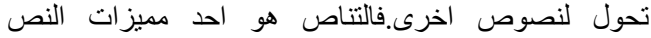
الأساسية و المتضمننصوص اخرى فالناص سابقة عنها او معاصرة لهات الها

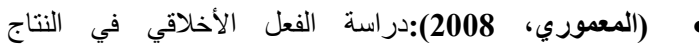
المعماري،و الاعتبار ات التي تحقق التميز في النتاج والتي ترنبط 


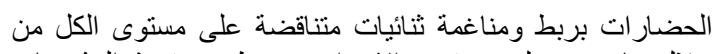

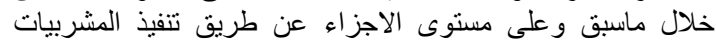

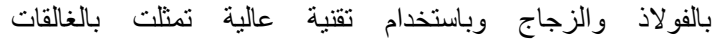

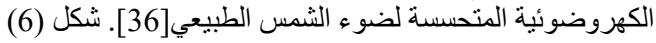

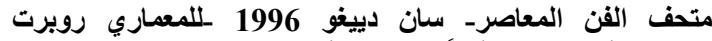
فنتوري:تأسس المبنى أو لاً كموطن للأعمال الخيرية بإسم (

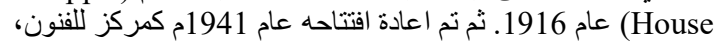
وتطور ليصبح مؤسسة ذات شهرة عالمية تضم اكثر من

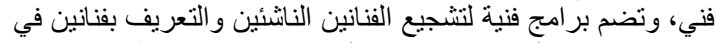

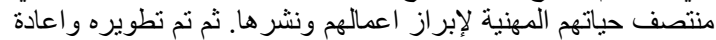

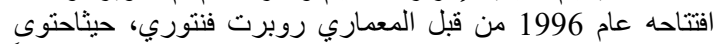
المبنى على إثنار ات لمبنى (Scripps House) التاريخي تأيبيداً

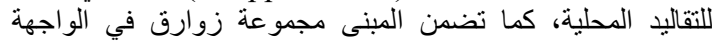

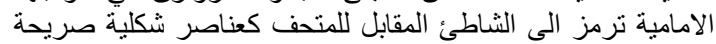

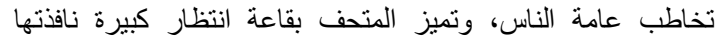
السقفية على شكل نجمة كبيرة[37].

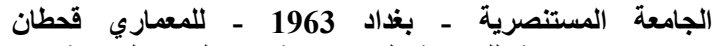
عوني:سميث نسبة للمدرسة المستنصرية في الفئهية الفترة العباسية عام

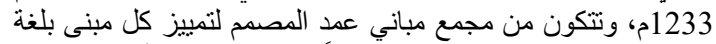

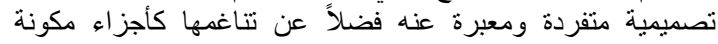

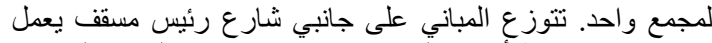

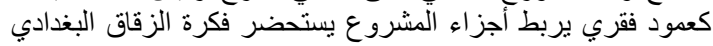

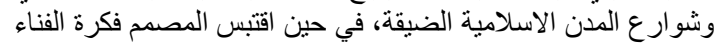

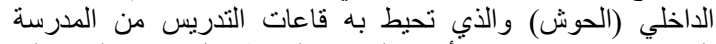

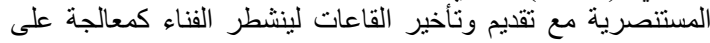

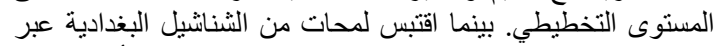

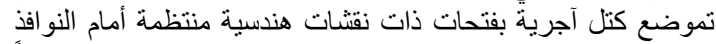

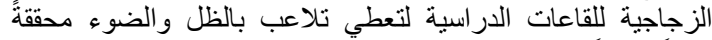

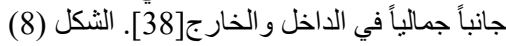

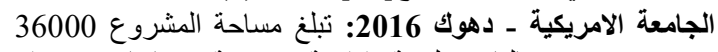

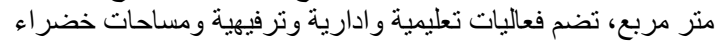

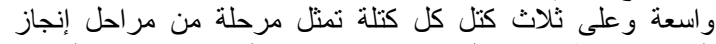
المشروع. يظهر في المشروع عناصر شلاص شكلية مقتبسة من العمارة

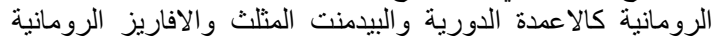

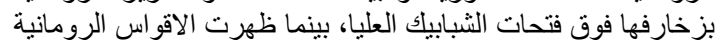

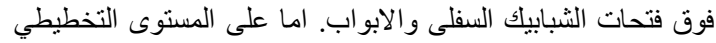

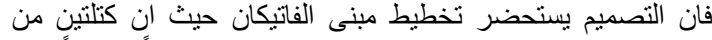

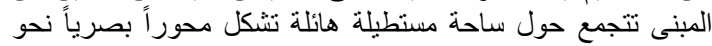

الكتلة الثالثة المسقفة بقبة من الطر از الرومانيـ[39]. الثنكل (9)
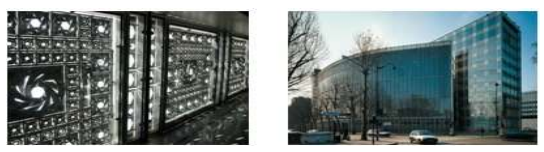

الثكل 5: معهد العالم العربي - باريس، المصدر : http://www.maroc.ma/ar/
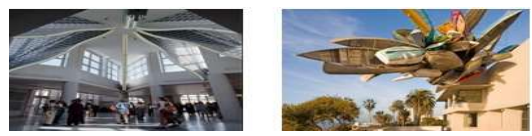

الثكل 6: متحف الفن المعاصر - سان دييغو، المصدر:

https://www.theguardian.com/artanddesign/2018/sep/23/r obert-venturi-obituary
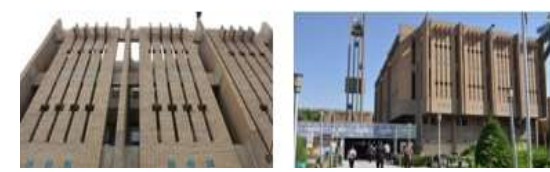

الثكل 7: الجامعة المستتصرية ـ بغداد، المصدر:

https://almadapaper.net/view.php?cat=161801

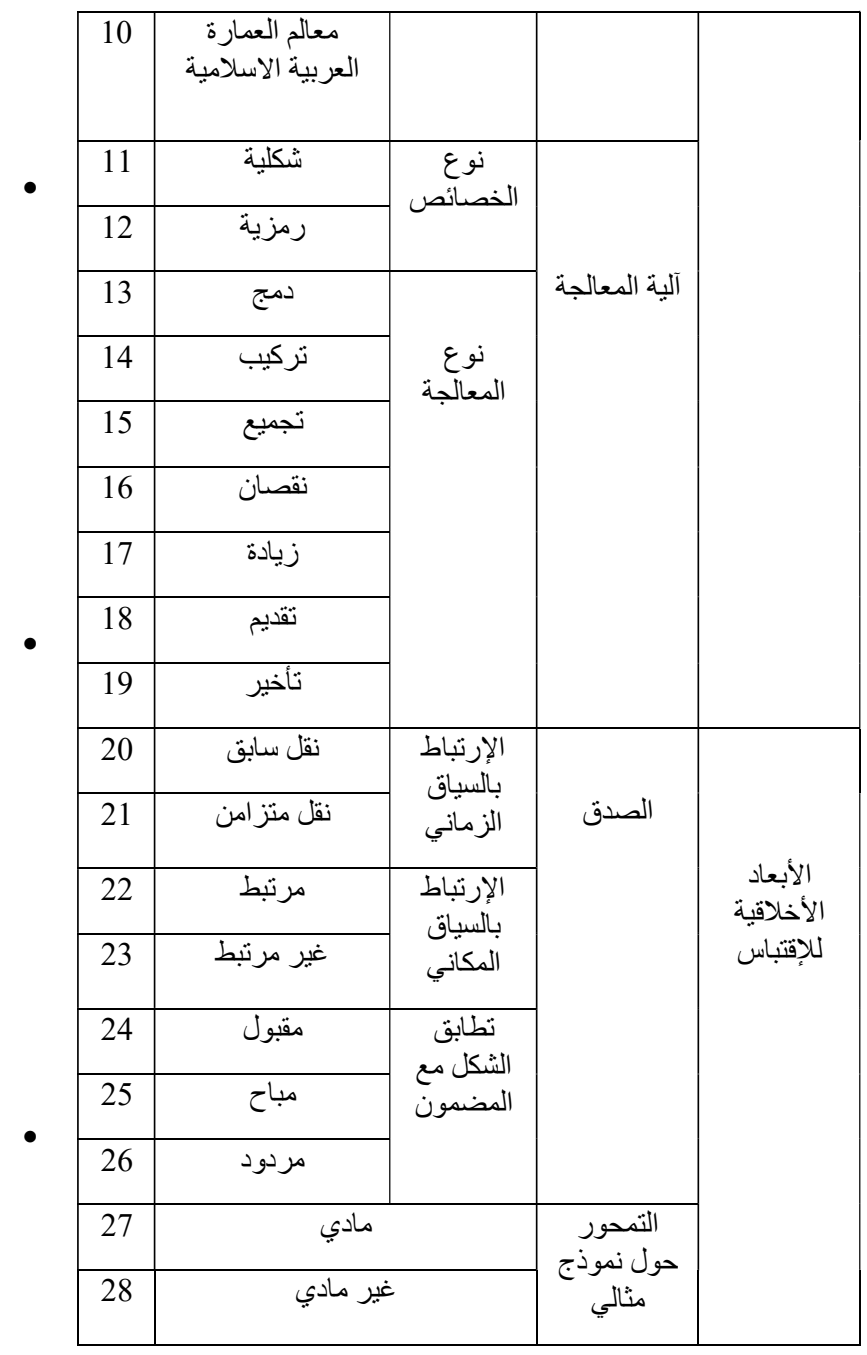

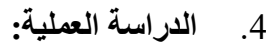

تتمثل الدر اسة العملية بتطبيق مفردات الاطار النظري على العينات المنتخبة

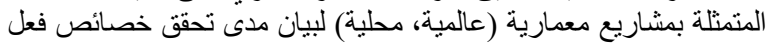
الاقتباس وتجلي الابعاد الاخلاقية اثناء صيرورنة.

1.4 تعريف العينات المنتخبة:

• معهل العالم العربي - باريس 1980 ـ للمعماري جان نوفيل:يعد هذا

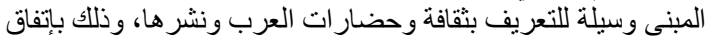

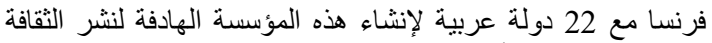

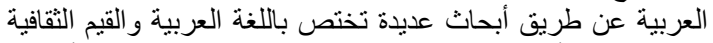

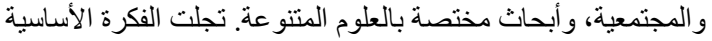

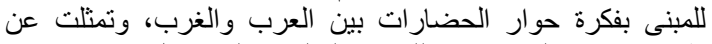

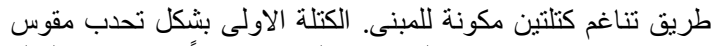

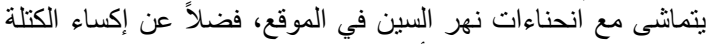

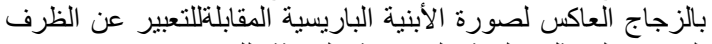

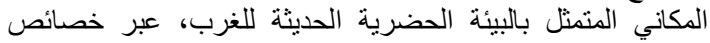

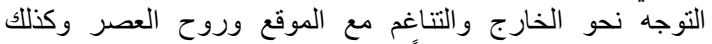
الاختزال في التفاصيل تعبير أ عن فكر الحداثة السائد. اما الكنلة الثنانية

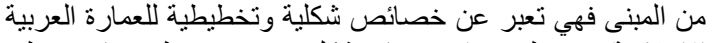

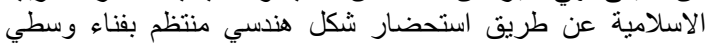

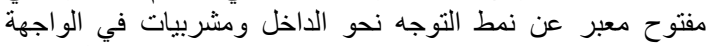

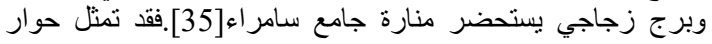


3.4 مناقشة النتائج: استخلصت هذه النتائج من نرابط مفردات الإطار

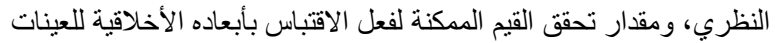
المنتخبة في التطبيق العملي، وكالآتي:

نوع العناصر المقتبسة:تصنف هذه العناصر وفقاً للدور الذي تؤديه

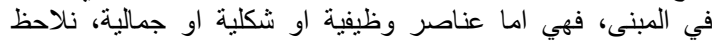

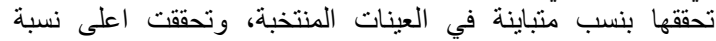

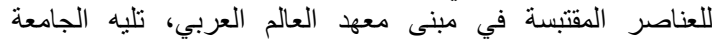

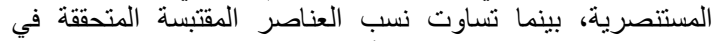
متحف الفن المعاصر و الجامعة الأمريكية.

آليات الإقتباس: تمثلت آليات الإقتباس بآليتي الإنتخاب والمعالجة

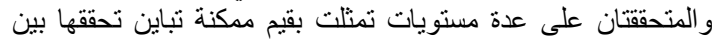

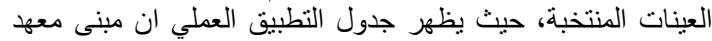

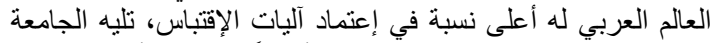

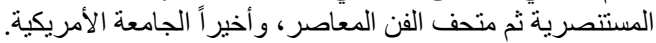

الأبعاد الاخلاقية للإقتباس:تتجلى الأبعاد الأخلاقية للإقتباس بمفردني

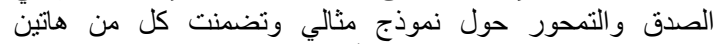

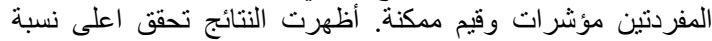

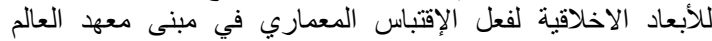

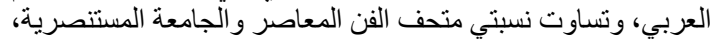
بينما ظهرت أقل نسبة في الجامعة الامريكية.

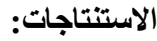

ـ ـ الاقتباس هو الفعل الناشئ من نقل الاشكال والافكار من داخل وخارج

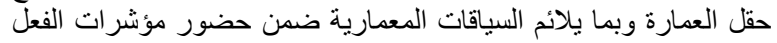
الاخلاقي في العمارة المتمثلة بالصدق، والتمات التحور حول نموذج مثنالي.

- يعد الاقتباس من ابرز الافعال في العمارة كونه الفعل المشكل الرئيس

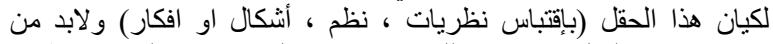
اخضاع هذا الفعل الاساسي للقيم الاخلاقية التي تحكمه ليحقق وظيفته

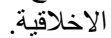

- يمثل تحقيق فعل الاقتباس الاخلاقي في العمارة احد تجليات القيم الاخلاقية في نتاجات الفعل الانساني.

- يمثل النتاج المعماري نسيج من اقتباسات لاتعيد نفسها بصورة مطلقة بل الإبل

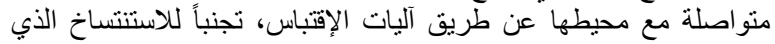
يقطع الصلة بالسياق الزماني و المكاني للمبنى.

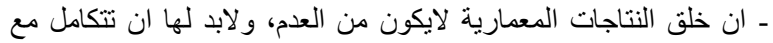

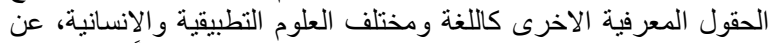

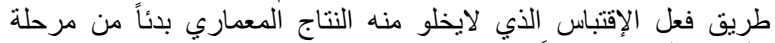

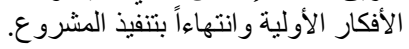

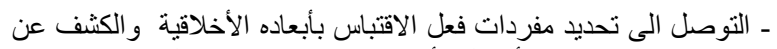

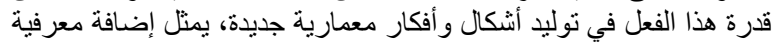

تعمل كدليل اولي للمصمم لفهم ماهية هذا الفعل المحوري في حقل العمارة فئل العمارة.

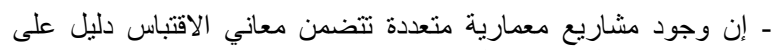

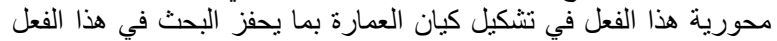
و التعمق بجانبيه المعماري و اللغوي.

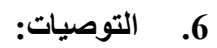

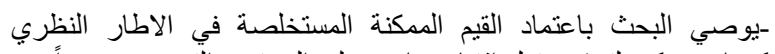

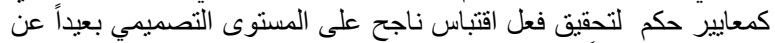
الاستنساخ،ومحققاً لوظيفته الاخلاقية للارتقاء بالنتاج المتاج المعماري.
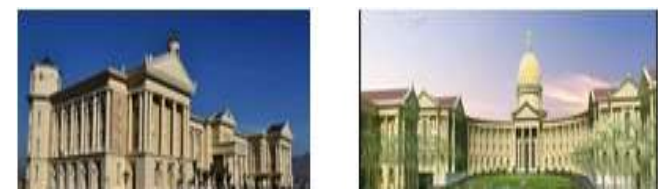

الثكل 8: الجامعة الامريكية ـ دهوك، المصدر:

https://kurk.com.tr/ar/projelerimiz

2.4: اختبار مؤشرات الإطار النظري على العينات المنتخبة:

\begin{tabular}{|c|c|c|c|c|}
\hline الامريكية & المستتصرية & متحف الفعن & العربي & المؤشر \\
\hline & $\theta$ & $\theta$ & $\theta$ & 1 \\
\hline \multirow[t]{2}{*}{$\theta$} & $\theta$ & & $\theta$ & 2 \\
\hline & & & $\theta$ & 3 \\
\hline$\theta$ & & $\theta$ & & 4 \\
\hline \multirow[t]{2}{*}{$\theta$} & $\theta$ & $\theta$ & $\theta$ & 5 \\
\hline & & $\theta$ & & 6 \\
\hline \multirow[t]{2}{*}{$\theta$} & $\theta$ & & $\theta$ & 7 \\
\hline & & & $\theta$ & 8 \\
\hline \multirow[t]{2}{*}{$\theta$} & & $\theta$ & $\theta$ & 9 \\
\hline & $\theta$ & & $\theta$ & 10 \\
\hline \multirow[t]{4}{*}{$\theta$} & $\theta$ & $\theta$ & $\theta$ & 11 \\
\hline & & & & 12 \\
\hline & & $\theta$ & & 13 \\
\hline & & & & 14 \\
\hline \multirow[t]{5}{*}{$\theta$} & & $\theta$ & $\theta$ & 15 \\
\hline & & & & 16 \\
\hline & $\theta$ & & $\theta$ & 17 \\
\hline & $\theta$ & & & 18 \\
\hline & $\theta$ & & & 19 \\
\hline \multirow[t]{3}{*}{$\theta$} & $\theta$ & $\theta$ & $\theta$ & 20 \\
\hline & & & $\theta$ & 21 \\
\hline & $\theta$ & $\theta$ & $\theta$ & 22 \\
\hline \multirow[t]{3}{*}{$\theta$} & & & & 23 \\
\hline & $\theta$ & & & 24 \\
\hline & & $\theta$ & $\theta$ & 25 \\
\hline$\theta$ & & & & 26 \\
\hline \multirow[t]{2}{*}{$\theta$} & & $\theta$ & $\theta$ & 27 \\
\hline & $\theta$ & & $\theta$ & 28 \\
\hline
\end{tabular}




$$
\begin{aligned}
& \text { [23]كريستيفا، جوليا:علم النص، ط1، تالت: فريد الزاهي، م:عبد }
\end{aligned}
$$

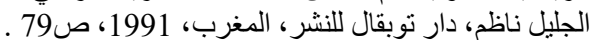

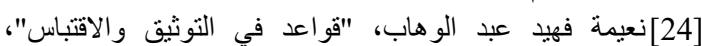

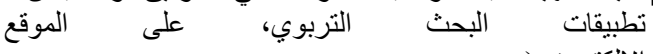

$$
\begin{aligned}
& \text { الالكتروني) }
\end{aligned}
$$

http://fac.ksu.edu.sa/sites/default/files/ltwthyq_f

$$
\text { (y_lmtn1.pdf }
$$

$$
\text { [25] نعيمة فهيد عبد الوهاب، مصدر سابق. }
$$

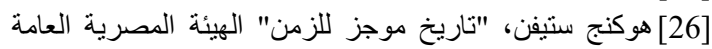

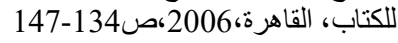

[27] Candelsonas Mario \& Morton David, "on reading Architecture", Reprinted from progressive architecture, March 1972.

[28] Frascari Marco, "The Particolareggiamento in the Narration of Architecture", Journal of Architectural Education 43/1, 1989.

[29] Gelernter, M. 1995 . Sources Of Architectural Form , Manchester university press, Manchester \& New York .,p.92-250

[30] http://mohameddawood.com/

[31] https://ar.lifehackk.com/39-robert-venturicelebrated-architect-of-postmodernism-1778765005

[32] http://www.bonah.org/

[33] https://www.imarabe.org/ar

[34] https://www.theguardian.com/artanddesign/2018 /sep/23/robert-venturi-obituary

[35] https://kurk.com.tr/ar/projelerimiz

[36] Jones, C.J. 1981. Design Methods, John Wiley and Sons Ltd., New York.,p.49-54

[37]Le Corbusier .1986 .Towrds A New Architecture, Dover Publications. New York .,p.225-265

[38] Sakamoto Takuzo, "Investigation and improvement of living environment in cave dwellings in china", 1986.

[39] William M. Taylor and Michael P. Levine, " Prospects for an Ethics of Architecture", published by Routledge, 711 Third Avenue, New York, NY 10017, 2011.

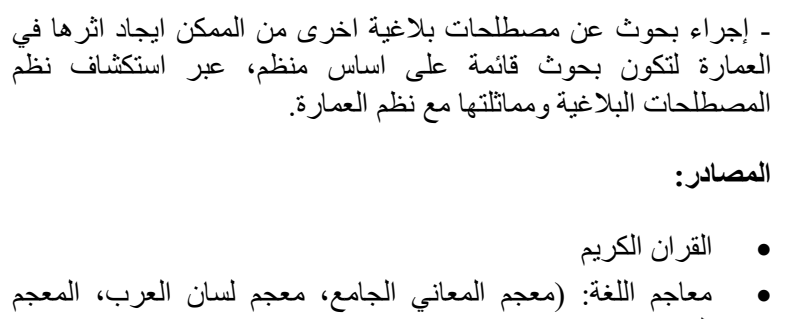

الر ائد). - (الرما

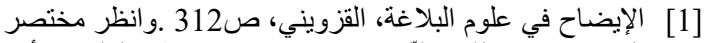

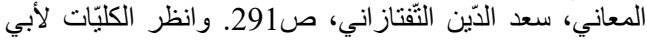

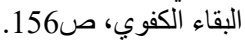

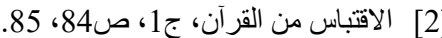

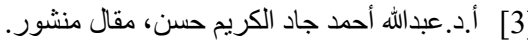

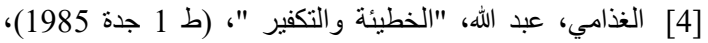

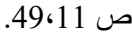

[5] النعيمي، ندى خضر، التناص في العمارة التفكيكية ، رسالة

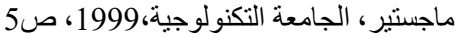

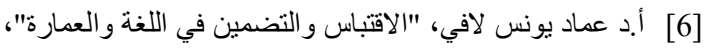

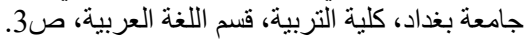

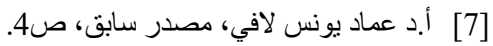

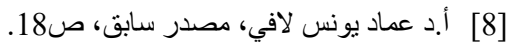

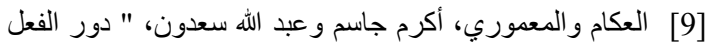

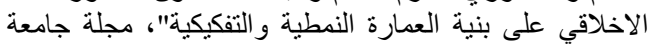

دمشق للعلوم الهندسية، المجلد 26، 26، العدد الاول، 2010، صن305،304.30

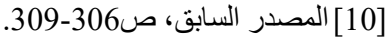

[11] المعموري، عبد الله سعدون، "الوظيفة الأخلاقية في العمارة-

دور الفعل الأخلاقي في بنية العمارة العربية الإسلامية

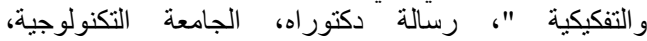

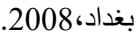

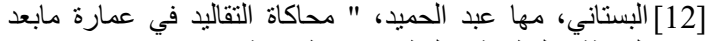

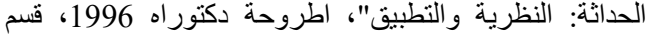

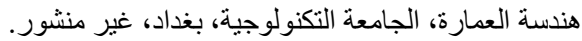

$$
\text { [13] [أ.د عماد يونس لافي، مصدر سابق. }
$$

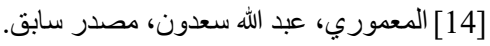

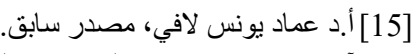

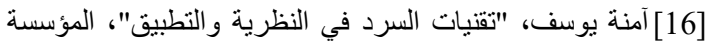

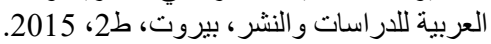

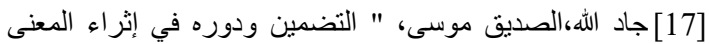

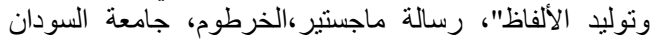

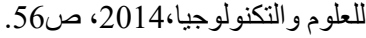

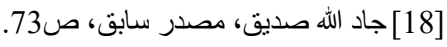

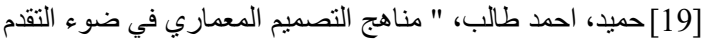

الفكري و التكنولوجي للانسان"، المجلة العبلة العر اقية لهندسة العمارة،

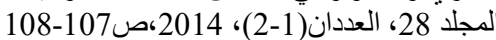

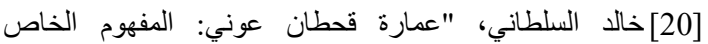

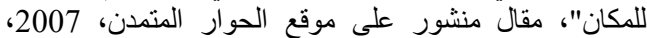

http://www.ahewar.org/debat/show.art.asp?aid=

$(107206 \& r=0$

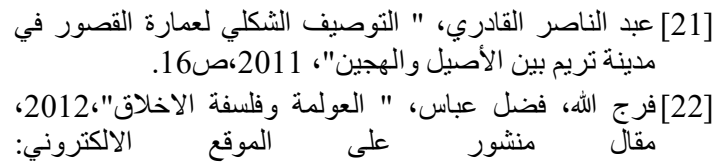

(https://www.sudaress.com/hurriyat/52535) 


\title{
Ethical Dimensions of Quotation in an Architectural Act
}

\author{
Abdullah Saadoun Al Maamouri ${ }^{1}$ and Nabaa T.M. AL-Khafaji ${ }^{2 *}$
}

${ }^{1}$ Department of Architecture engineering, University of Technology, Baghdad, Iraq, abdullah.asadoon@yahoo.com

2 Department of Architecture engineering, University of Technology, Baghdad, Iraq, 90873@student.uotechnology.edu.iq

*Correspondingauthor: NabaTaher Muhammad Al-Khafaji,Email: 90873 @ student.uotechnology.edu.iq

Published online: 31 December 2020

Abstract_The ethical dimensions of quotation in an architectural act emerged as a standard judgment in the differentiation between architectural products, the importance of quotation emerges as a basic act in creating the architecture entity, which represents a field that has common boundaries with the edges of other sciences, Architects depend on quoting from various cognitive fields to enrich their work (such as the field of language, various applied and humanity sciences), So achieving this act must be subjected to the ethical dimensions that govern its creating process to fulfill ethical function in architecture. The research problem emerged as " ambiguity of knowledge about the ethical dimensions of the quotation in the architectural act ", The aim of the research to set a general framework for the ethical dimensions of the quotation and activate them by the designer in the architectural act. The research adopted a descriptive approach based on the analysis of previous studies related to the act of ethical quotation and extracted three basic levels represented by the vocabulary of quotation: the types of quoted elements, the mechanisms of quotation and the moral dimensions of quotation as an ethical act. These indicators were applied to selected samples represented by (global and local) projects, discussing the results down to the final conclusions and recommendations to the ethical quotation act that enrich the design process from ideas to final results.

Keywords: Quotation, Ethical dimensions, Architectural act. 